\title{
Genetic and environmental sources of individual differences in non-verbal intelligence in Russian adolescents
}

\author{
Sergey Malykh ${ }^{1, *}$, Ivan Voronin $^{1}$, Victoria Ismatullina $^{1}$, Ilia Zaharov $^{1}$, Alexandra Belova ${ }^{1}$ and Marina Lobaskova ${ }^{1}$ \\ ${ }^{1}$ Psychological Institute of Russian Academy of Education, 125009, Moscow, Russia
}

\begin{abstract}
Current study aimed to estimate the impact of genetic and environmental factors in the individual differences in non-verbal ability in Russian adolescents. The sample included 580 twins. Nonverbal ability was assessed by means of Standard Raven's Progressive Matrices. Individual differences in non-verbal ability were explained almost entirely by family environment $(65 \%)$ and person-specific environment (29\%).
\end{abstract}

\section{Introduction}

The sources of individual differences in cognitive abilities have been one of the major concerns of behaviour genetics since the very beginning of the field. Intelligence is a quantitative characteristic which represents the variance shared by specific cognitive abilities [1]. The performance in very different cognitive tasks (like verbal and non-verbal tasks) correlates at the level 0.3. The common variance of cognitive tasks extracted by means of factor analysis was named general intelligence, or $g$. It explains over $40 \%$ of individual differences in cognitive performance [2].

Intelligence is one of the most reliable characteristics of human behaviour. Individual differences in intelligence remain stable through the lifespan [2]. Intelligence turned up to be an important predictor of academic achievement, social and career outcomes [3], this is why the sources of individual differences have been studied extensively.

First attempt to study genetic and environmental aetiology of individual differences in intelligence was performed by F.Galton in XIX century [4]. It was followed by the large batch of behaviour genetic research of intelligence on various populations in different age groups. The heritability (percent of individual differences accounted for genes) of intelligence vary from $40 \%$ to $80 \%$ [5], the estimate from the large meta-analysis of twin studies is roughly $50 \%$ [6-8]. Most of these studies were made in USA and Western Europe, but similar estimates were obtained from the studies in Russia, East Germany, Japan, and India [5].

About $50 \%$ of the individual differences in intelligence are accounted for environmental effects. Environmental effects shared by family members (shared environment) are important in childhood, but almost disappear by adulthood. On the contrary, the role of genes increases in course of cognitive development $[9,10]$. The mechanism of gene-environment correlation was proposed to explain this trend: children are exposed to the environmental conditions which are most appropriate to their genetic predispositions $[11,12]$. In early childhood this mechanism is driven by parents who respond to child's behaviour [13]. Later in the individual development the child starts to choose the environments actively.

The genetic nature of intelligence was uncovered in multivariate twin studies which showed that the correlations between the scores in various cognitive tasks are explained largely by genes $[14,15]$. The same genes, but different environments explain variability in different cognitive abilities. The study also shows that genetic structure of the Wechsler Intelligence Scale for Children sub-test scores reproduces hierarchical structure of intelligence with Cohen factors (verbal comprehension, perceptual organisation, and freedom from distractibility) at the first level, and factor of general intelligence at the second level [16].

Current study aimed to estimate the impact of genetic and environmental factors in the individual differences in non-verbal ability in Russian adolescents.

\section{Sample and methods}

The sample included 580 Russian twins (262 MZ, 176 same-sex DZ, 142 opposite-sex DZ) aged 10 to 14 years (mean age 12.3 years, $\mathrm{SD}=1.4$ years). 277 participants were male, 303 participants were female.

Non-verbal ability was assessed by means of Standard Raven's Progressive Matrices [17]. The test includes 5 sets of 12 tasks each. Each task displays a matrix with a missing element. A participant is asked to decipher the regularity and choose an element which completes the pattern. The difficulty of tasks within and across task sets increases. Set A includes tasks which

Corresponding author: malykhsb@,mail.ru 
require finding missing part of a pattern and involves ability to differentiate the elements of a structure, to find relationships between elements. Set $\mathrm{B}$ requires understanding analogy between pairs of figures. Set C comprises the tasks with evolving patterns. A participant must recognise the trends of evolvement in vertical and horizontal dimensions of a matrix and sum up these trends. Set D requires understanding qualitative and quantitative patterns. The most difficult set $\mathrm{E}$ involves analytic and synthetic mental processes.

We used twin method to disentangle genetic and environmental effects of non-verbal ability. Twin method is based on the comparison of monozygotic (MZ) and dizygotic (DZ) twin pairs $[1,18]$. The method assumes that observed similarity within twin pair comes from 1) genes shared by twins and 2) family environment shared by twins. MZ and DZ twins share both genes and family environment. However, MZ twins have identical genetic code, and DZ twins share only $50 \%$ of segregating genes. This is why DZ twins are usually more dissimilar than $\mathrm{MZ}$ twins. The difference in similarity of MZ and DZ twins suggests that the twins resemble because of shared genes and the phenotypic individual differences have genetic component. If $\mathrm{MZ}$ and DZ twins are similar to same extent, we can suggest shared environmental effects. Some environmental factors-person-specific, or non-shared environmentalways make twins more dissimilar. Person-specific environment explains why MZ twins are never completely identical in any behavioural characteristic.

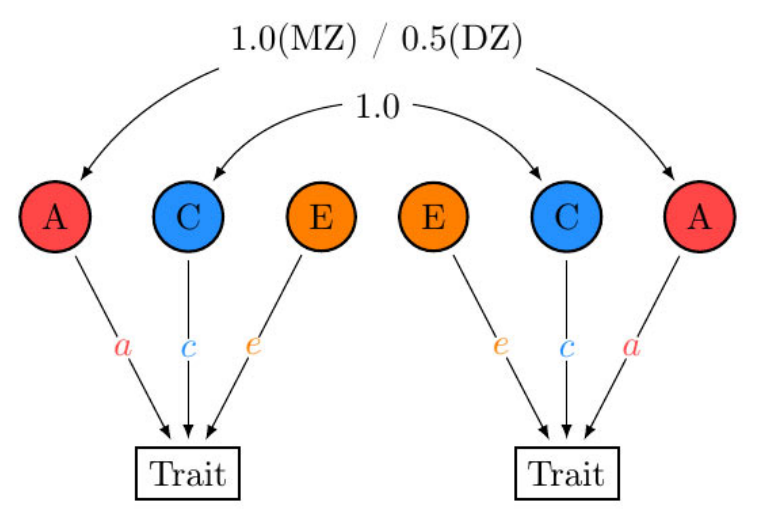

\section{Twin $1 \quad$ Twin 2}

Fig. 1. Path diagram for the univariate twin model

Early twin research used cross-twin correlations to compute the impact of genes and environment to the phenotype [19]. Modern twins studies use structural equation modelling to obtain the estimates of genetic and environmental effect [20]. Modelling approach brings many advantages, such as models comparison, estimation of genetic and environmental effects on the covariation of several phenotypes, study of genetic and environmental aetiology of phenotypic stability and change. The univariate twin model is depicted in Figure 1. Squares denote measured phenotypic variable in Twin 1 and Twin 2, circles denote unobserved genetic (A), shared environmental (C), and person-specific (E) environmental effects. Single-headed arrows specify causal effects; double-headed arrows specify correlations. $a, c$, and $e$ are model's parameters estimated in the process of model fitting. These parameters specify the amount of genetic and environmental variance in the total variance of the phenotype.

We fit a univariate twin model on the Raven's total score to estimate genetic and environmental effects on non-verbal ability. Data preparation and twin analysis were performed by means of $\mathrm{R}$ environment for statistical computations [21] and OpenMx package for $\mathrm{R}$ [22].

\section{Results}

Descriptive statistics for Raven's total score and the scores in task sets are displayed in Table 1. The decrease of the scores across task sets reflects progressive increase of series difficulty. At the same time participants' responses cover all the range of possible scores. The variability of Raven's total score is sufficient for further analysis of the structure of individual differences of non-verbal ability.

Table 1. Descriptive statistics for Raven's scores

\begin{tabular}{lcccc}
\hline & N & M (SD) & Median & Range \\
\hline A & 540 & $10.53(1.53)$ & 11.00 & $2.00-12.00$ \\
B & 540 & $9.66(2.21)$ & 10.00 & $0.00-12.00$ \\
C & 537 & $7.46(2.77)$ & 8.00 & $0.00-12.00$ \\
D & 527 & $7.84(2.59)$ & 8.00 & $0.00-12.00$ \\
E & 481 & $4.17(2.71)$ & 4.00 & $0.00-11.00$ \\
Total & 529 & $39.52(9.37)$ & 41.00 & $11.00-57.00$ \\
score & & & & \\
\hline
\end{tabular}

Raven's total score was associated with age $(\mathrm{r}=0.198, \mathrm{p}=0.001)$. We adjusted test score for age to avoid bias. There were no statistically significant sex differences in mean test performance $(\mathrm{F}[1,263]=0.563$, $p=0.454)$, however there was statistically significant difference in variance across sex groups $(\mathrm{F}[1,263]=$ $4.708, p=0.031)$. Visual inspection of the Raven's total score histogram allowed to come to a conclusion that there were no outliers and score was distributed normally.

The cross-twin correlations of Raven's total score were 0.73 for $\mathrm{MZ}$ and 0.69 for $\mathrm{DZ}$ twins (after introducing adjustment for age 0.72 and 0.67 , respectively). High similarity of $\mathrm{MZ}$ twins suggests limited effect of person-specific factors on individual differences of non-verbal ability. DZ twins are almost as similar as MZ twins bearing evidence that the effect of genes on non-verbal ability is nonexistent.

Univariate twin model showed good fit $\left(\chi^{2}[6]=\right.$ $2.510, \mathrm{p}=0.867)$. Genetic factors explained $7 \%(95 \%$ CI: $0-28 \%$ ) of the variance of Raven's score, $65 \%$ (46- 
$75 \%$ ) were accounted for family environment, and $29 \%$ (22-37\%)-for person specific environment.

\section{Discussion}

In current study we investigated genetic and environmental aetiology of non-verbal ability in Russian adolescents. We found that individual differences in nonverbal ability are explained by environmental factors almost entirely. Family environment is especially important. On the contrary, genes have negligible effect on non-verbal ability.

Low heritability estimate obtained in current study is remarkable as previous studies of non-verbal ability in adolescence show higher estimates (30-70\%) [23-27]. However, non-verbal abilities in these studies were measured by means of test batteries: WISC-III [24], WISC-R [25,27] CAT3 [26]. The studies on Russian samples also show higher heritability of cognitive abilities. Heritability of non-verbal ability in early school years measured by Standard Raven's Progressive Matrices was 89\% [28]. Grigorenko et al. [29] obtained $49 \%$ heritability of WAIS-III Performance IQ. Additive genetic influences accounted for approximately the same amount of variance in verbal, performance and full-scale IQ data - $86 \%, 84 \%$ and $89 \%$, respectively, for Russian adults [30].

Two mechanisms can explain exceptionally low heritability of non-verbal ability in current study. First mechanism is assortative (or non-random) mating [30]. People with similar educational level mate more frequently, and the latter correlates with intelligence which is highly heritable. Under effect of assortative mating spouses share some genetic variation, so DZ twins share more than $50 \%$ of segregating genes. This mechanism inflates DZ similarity and reduces the difference between $M Z$ and DZ correlations. The similarities of DZ twins in Russian studies mentioned above are 0.58 [29] and 0.62 [28] which is higher than similarity of adolescent DZ twins from Netherlands and US (0.19-0.27) [24,25].

Gene-environment correlation is another possible explanation of low heritability of non-verbal ability in Russian adolescents. The effect of gene-environment correlation emerges when parents adjust their own behavior and child's environment as a response to child's genetic propensities manifested in phenotype. The interplay of genes and environment is an essential part of cognitive development [32]. At the early stage of individual development parents set up child's environment as a response to child's behavior [13]. Adolescents can actively choose their occupation and environments. In adolescence the effect of geneenvironment correlation is more prominent under diverse and cognitively stimulating environment [33].

The effect of gene-environment correlation increases resemblance of genetically similar relatives and reduces resemblance of genetically dissimilar relatives. In twin study this express in higher MZ similarity and lower DZ similarity and higher impact of genes. Low heritability of non-verbal ability in current study can be accounted for the deficiency of gene-environment correlation resulted from specificity of parenting in Russia, specificity of education, or lower socio-economic status of families [34].

To summarize, current study suggest that individual differences in non-verbal ability in Russian adolescents are almost entirely explained by (family and personspecific) environmental factors. Further study is needed to clarify the nature of unexpectedly low heritability estimate.

\section{References}

1. R. Plomin, J.C. DeFries, G.E. McClearn, P. McGuffin, Behavioral Genetics (New York: Worth Publishers, 2013).

2. I.J. Deary, L.J. Whalley, H. Lemmon, J. Crawford, and J. M. Starr, Intelligence, 28, 49 (2000).

3. T.A. Salthouse, in Underst. Hum. Dev., 265-287 (Springer, 2003)

4. B.S. Burks, in Meas. Intell., 325-357 (Springer Netherlands, 1973)

5. H.M. Chipuer, M.J. Rovine, and R. Plomin, Intelligence, 14, 11 (1990)

6. J.C. Loehlin, Am. Psychol., 44, 1285 (1989)

7. J. C. Loehlin, J. M. Horn, L. Willerman, Child Dev., 60, 993 (1989)

8. T.J. C. Polderman, B. Benyamin, C. A. de Leeuw, P. F. Sullivan, A. van Bochoven, P.M. Visscher and D. Posthuma, Nat Genet, 47, 702 (2015).

9. T.J. Bouchard, Ann. Hum. Biol., 36, 527 (2009)

10. T.J. Bouchard, Twin Res. Hum. Genet., 16, 923 (2013)

11. R. Plomin, J. C. DeFries, J.C. Loehlin, Psychol. Bull., 84, 309 (1977)

12. D.A. Briley and E.M. Tucker,-Drob, Psychol. Sci. 24, 1704 (2013).

13. E. M. Tucker, Drob and K. P. Harden, Dev. Sci., 15, 250 (2012).

14. S.D. Casto, J.C. DeFries D.W. Fulker, Behav. Genet. 25, 25 (1995).

15. I.J. Deary, F.M. Spinath T.C. Bates, Eur. J. Hum. Genet. 14, 690 (2006).

16. F.V. Rijsdijk, P.A. Vernon, D.I. Boomsma, Behav. Genet., 32, 199 (2002).

17. J. Raven, Cognit. Psychol., 41, 1 (2000)

18. I. Voronin, V. Ismatullina, I. Zakharov, G. Vasin, S. Malykh, ITM Web Conf., 6, 02010 (2016).

19. D.S. Falconer, T.F.C. Mackay, Introduction to Quantitative Genetics (Pearson, Prentice Hall, Harlow, 2009)

20. F. V. Rijsdijk and P. C. Sham, Brief. Bioinform. 3, 119 (2002)

21. R. Core Team, R: A Language and Environment for Statistical Computing (Vienna, Austria, 2016)

22. M.C. Neale, M.D. Hunter, J.N. Pritikin, M. Zahery, T.R. Brick, R.M. Kirkpatrick, R. Estabrook, T.C. Bates, H.H. Maes, and S.M. Boker, Psychometrika, 81, 2, 535 (2015) 
23. N. Jacobs, S.V. Gestel, C. Derom, E. Thiery, P. Vernon, R. Derom, and R. Vlietinck, Behav. Genet. 31, 209 (2001)

24. I.L.C. van Soelen, R.M. Brouwer, M. van Leeuwen, R.S. Kahn, H.E. Hulshoff Pol, and D.I. Boomsma, Twin Res. Hum. Genet. 14, 119 (2011)

25. R.S. Betjemann, E.P. Johnson, H. Barnard, R. Boada, C.M. Filley, P.A. Filipek, E.G. Willcutt, J.C. DeFries, and B.F. Pennington, Behav. Genet., 40, 135 (2010)

26. C.M. Calvin, I.J. Deary, D. Webbink, P. Smith, C. Fernandes, S.H. Lee, M. Luciano, and P.M. Visscher, Behav. Genet. 42, 699 (2012)

27. K. Silventoinen, W. G. Iacono, R. Krueger, and M. McGue, Behav. Genet. 42, 393 (2011).

28. Y. Davydova, V. Ismatullina, I. Voronin, O. Ovcharova, E. Sabirova, S. Malykh, Prosedia Social and Behavioral Sciences, 86, 419 (2013)
29. E.L. Grigorenko, M.C. LaBuda, and A. S. Carter, Acta Genet. Medicae Gemellol. Twin Res. 41, 65 (1992)

30. S.B. Malykh, N.V. Iskoldsky, E.D. Gindina, Personality and Individual Differences, 38, 1475 (2005)

31. L.J. Eaves, A. C. Heath, and N. G. Martin, Behav. Genet. 14, 371 (1984)

32. U. Bronfenbrenner and S. J. Ceci, Psychol. Rev. 101, 568 (1994)

33. P.E. Turkheimer and P. E. E. Horn, in Behav. Genet. Cogn. Lifesp., edited by D. Finkel and C. A. Reynolds, pp. 41-68 (Springer New York, 2014)

34. E.M. Tucker-Drob, D.A. Briley, and K.P. Harden, Curr. Dir. Psychol. Sci. 22, 349 (2013) 